\title{
How Do Cubans Use Internet? The Effects of Capital
}

\author{
Xuefei (Nancy) Deng \\ California State University, \\ Dominguez Hills \\ ndeng@csudh.edu
}

\author{
Armando Camacho \\ Independent Researcher \\ arcamcos68@gmail.com
}

\author{
Larry Press \\ California State University, \\ Dominguez Hills \\ lpress@csudh.edu
}

\begin{abstract}
We conducted an exploratory study to understand Cuban Internet use from individual viewpoint. Drawing upon Bourdieu's Capital Theory, this study seeks to understand forms of capital that affect Cubans' Internet access and use. We collected data from online survey posted on a Cuban blogging site and analyzed the narratives of 82 Cuban citizens who shared their Internet use experience. Our data analysis shows that economic and cultural capital are the key factors influencing Cuban's Global Internet and domestic Intranet access, which in turn influenced the development of their social and technical capital. Moreover, our analysis reveals Cuban's value in Internet access for communication and knowledge acquisition, and reveals their improvisation behaviors when they experienced access barriers. Suggestions for future research on Cuban Internet use are discussed.
\end{abstract}

\section{Motivation: Internet use in Cuba}

In a networked world where citizens of developed countries enjoy the affordable and ubiquitous Internet access and social media technologies, it's difficult for us to imagine a place on the Earth where getting online is not only a luxury but also a challenge. According to a BBC News article published in February 2016, only about $5 \%$ to $25 \%$ of the entire 11.48 million Cubans have any type of Internet service; this makes the Caribbean nation one of the world's least connected countries [6]. Among the barriers to Internet access are high prices, slow connection speed, and extensive government regulations. In 2015, Cuban government opened 35 public WiFi hotspots to provide Internet access in Havana and other parts of the country. Today there are $421 \mathrm{WiFi}$ hotspots and 258 public-access "navigation rooms" across the island nation, according to Cuba's state-owned telecom provider, Empresa de Telecomunicaciones de Cuba S.A. (ETECSA).
However, the cost of Internet access remains daunting for majority of the Cuban citizens: for the slow Internet connection, Cubans were charged \$2 per hour, which was equivalent to about one-tenth of a Cuban's average monthly salary [6]. Now, the cost has been reduced to 1.5 CUC (equivalent to \$1.5) per hour, according to ETECSA. (CUC is Cuba's tourist currency, which is tied to the U.S. dollar).

In recent years, Cuban Internet infrastructure has witnessed modest improvement, including the installation of an undersea cable connecting Cuba and Venezuela in 2015, and the $3 \mathrm{G}$ mobile trial by ETECSA in a small area of Cuba. Now the $3 \mathrm{G}$ is more widely available, but it requires a compatible phone [19]. To get online in Cuba, people have to find a public-access location, buy WiFi access and get a little piece of paper with a login and password, and wait for the slow rendering of webpages. The frustration with the slow Internet speed was shared by foreign visitors such as a Fortune News reporter named Erin Griffith, who made a 3-day trip to Cuba in April 2016 to report on former U.S. President Obama's historic visit to Cuba. Ms. Griffith expressed her frustration and anxiety during the one hour of trying to go online from a WiFi hotspot in La Rampa, a six-block long stretch of the 23rd street in Havana. Ms. Griffith vividly described [8]:

"I enter the 12-digit user name and 12-digit password from my paper slip and wait. The operation fails. I type it in again. And then again. I realize I should have charged my laptop for this. Eventually the spinny wheel stops. I have been rejected. I enter my user name and password three more times, each time more determined.... I am not giving up. I have already come this far.....This is going to be the time. I can feel it. ... I type in my 12-digit login and 12-digit password for what must be the 100th attempt. ... Hemingway never wasted an hour wrestling with crappy Wi-Fi. I smash an ant crawling across my screen with my login paper..." [Reported from Havana, Cuba, $4 / 22 / 2016]$ 
For the Internet access, Cubans need to make trips to the limited number of WiFi hotspots or "navigation rooms" across the island country. As Ms. Griffith made the remark, "People don't get on the Internet in Cuba... They 'go to Internet.' .... g guess if it rains, people in Havana simply don't go to Internet." Although we can find some Internet-related statistics on Cuba from world organizations such as the International Telecommunication Union (ITU) and the World Bank, their statistics are based on reports of the Cuban Ministry of Communication so our understanding of Cuban citizens' Internet use behaviors remains limited.

However, understanding individual use behaviors and capturing user values from their use experience have positive impacts on the design of information and communication technology [7]. This understanding is especially important in Cuba, a developing country where the state-owned telecom ETECSA (http://www.etecsa.cu/) remains one of the few government monopoly suppliers of telephone, mobile and Internet services in the world [18]. Thus, in this study, we focus on those Cubans with any types of Internet services (including both Internet and Intranet) to understand their experience with and perceptions about their Internet use.

To achieve the research objective, we adopt Bourdieu [2]'s concept of capital, the material and symbolic resources that are essential to the competition. In Cuba, resources for Internet connectivity are limited, making the lens of capital appropriate for the study. Hence, drawing upon Bourdieu's Capital Theory [1], this study focuses on individual viewpoints and seeks to reveal the various forms of capital that affect Cubans' Internet access and use behaviors. More specifically, this study addresses the following two questions: (1) What patterns have Cubans demonstrated with their Internet/Intranet use? (2) What forms of capital do Cubans believe affect their Internet/Intranet use?

Data collection was performed by one of the coauthors from Cuba. The analysis of the qualitative data collected from 82 Cubans' narratives suggested that economic and cultural capital were key factors contributing to their Internet and Intranet access while social and technical capital turned out to be the key consequences of their Intranet/Internet use. Moreover, our analysis reveals Cuban's value in Internet access for communication and knowledge acquisition, and reveals their improvisation behaviors when experiencing access barriers. Findings of the study provide some useful insights into the emerging Internet adoption and use phenomenon in Cuba, and enhance our understanding of digital divide in a different national context.

\section{Investigative context: Internet in Cuba}

\subsection{History and current development}

Cuba is considered as one of the few countries remaining on the Earth that still restricts its citizens' access to the global telecommunication network. It is ranked poorly in two key indices of information and technology development: the Freedom House Freedom on the Net score (FON), and the information and communication technology (ICT) Development Index (IDI) by the International Telecommunication Union (ITU). The FON is a function of obstacles to Internet access, limits on content and violations of user rights. Only five of 65 nations are rated as less free than Cuba. The IDI is a function of user access, use and skills. In 2016 Cuba's IDI is ranked 135th of 175 nations in the world [11].

According to the ICT statistics reported annually by ONEI, the Cuban Office of Statistics and Information, 4,539,200 people in Cuba have access to the "Internet," but they are counting people with access to the global Internet plus people with access to Cuba's domestic Intranet [21]. Moreover, the term "user" is not defined in the Internet-related statistics by ONEI: it is not clear who they are counting as an Internet "user." Does it refer to anyone who has purchased access time once during the year, people who theoretically have access to the Intranet at work or school, etc.? Although the number of users of the global Internet was not reported, the government claimed that one million people have permanent accounts with ETECSA, Cuba's monopoly ISP [22]. This could give us a rough estimate about $10 \%$ of Cuban population with global Internet access. Finally, it should be noted that the vast majority of those with access to the global Internet do so over dial-up or slow (up to $1 \mathrm{mbps}$ ) WiFi links.

We can place the Cuban Internet in a regional context by considering the Human Development Index (HDI) compiled by the United Nation's Development Program and the ICT Development Index (IDI) compiled by ITU. The HDI is a function of income, health and education, and Cuba's HDI is the tenth highest among the 33 nations of Latin America and the Caribbean. (It was second only to Chile as of 2011). Despite that relatively high rank, Cuba's IDI is the lowest in Latin America and the Caribbean, suggesting the lowest level of ICT development in the region [11].

The sad state of the Cuban Internet is a product of its history. Cuba connected to the Internet shortly after the fall of the Soviet Union, which Cuban government contributed it partially to the Soviet glasnost (openness). The Soviet Union's collapse also triggered a Cuban economic crisis caused by the end of Soviet 
subsidy [15]. Both the political fear and funding shortage led Cuba to highly restricting the Internet access.

Today, the Cuban Internet has opened slightly. The economy is hurting to a lesser degree because of the Venezuelan crisis, and the Cuban government has learned to censor the Internet and use it for surveillance and propaganda. The state-owned telecom ETECSA (http://www.etecsa.cu/) is one of the few government monopoly suppliers of telephone, mobile and Internet services in the world [18]. Over the last few years, ETECSA has created public access WiFi hotspots. Moreover, it has offered home "broadband" service in a small portion of Havana: as of April 2017 there were 358 paying customers [20]. Meanwhile, 3G coverage has increased in the country [19]. Although reaching only a small part of the population and using obsolete technology, these efforts indicate a change in attitude in Cuba and are of symbolic importance.

The most significant improvement in the Cuban Internet was the installation of an undersea cable connecting Cuba and Venezuela in 2015. It has become a strong link in a very weak chain leading to Cuban users. Another recent development is Google's installation of caching servers in Cuba, which will speed up the access to YouTube and other Google services [17]. Marginally improved access to Google services is of little value, but allowing Google caching servers may signify a shift in Cuban Internet policy and policy on dealing with a US company.

\subsection{Technology education and profession}

Cuban policy emphasizes education and health care, which compensates for a relatively poor economy in determining their HDI. Their emphasis on education drives the relatively high HDI skill component, offsetting low access and use ratings. According to the ITU's ranking of 175 countries, Cuba is ranked 135 in ICT Development Index (IDI), 167 in Access, 150 in use, and 57 in skills.

Cuba provides free, universal education (9 years is the mandatory minimum) to its citizens, one of the major "fruits of the Cuban revolution." According to the most recent statistics published by UNESCO report, Cuba invests $12.84 \%$ of GDP in education and has achieved a $99.7 \%$ literacy rate for people at 15 years and older, achieving the top rate for Latin America and the Caribbean and in the top ten percent of all nations (http://en.unesco.org/countries/cuba). In the long term, Cuba government plans to connect all high schools, polytechnic institutes, junior high schools, day care centers, special schools and primary schools and all teachers to the Internet by 2019. They have not specified the connectivity technology and may not meet their goal, but it is consistent with their stated values.

In the higher education, Cuba has 17 universities and 25 professional and technical schools that offer specialization in information and communication technology. The most prominent of these is UCI, the specialized University of Informatics Science (https://www.uci.cu/). UCI and other universities have trained workers for state-owned companies and for the nascent Cuban startup community. The five-year UCI curriculum mixes coursework and practical experience with the goal of graduating working professionals $[15,16]$. For example, UCI faculty and students collaborated with Google on the installation of Google Global Cache servers in Cuba [17].

At the national level, there is a unique organization called the Cuban Youth Computer Clubs. The organization was first established by the government in 1971, and later was renamed as the Youth Computer and Electronics Clubs in 1987. The Clubs provide recreation (games) and technical training at 600 locations nationwide and claim to serve 35,000 visitors on a monthly basis. The Youth Computer Clubs network (TinoRed) was one of the first four computer networks in Cuba [16]. In addition, an organization called "Information Science Professional Society" organizes conference and workshops and works closely with universities such as UCI. It recently organized a conference aimed at promoting the collaboration between state-owned software companies and selfemployed programmers in Cuba. Although the startup community was initially seen as competitors to the state-owned software companies, the efforts by the organization have contributed to a shift in viewing independent software entrepreneurs as potential collaborators of state-owned software companies.

We are also witnessing the emergence of an information technology (IT) profession. Cuba has legalized self-employment in 201 occupations, among them computer programmers. There are now 1,432 licensed programmers [20]. The number of active, registered programmers in Cuba has grown at an increasing rate every year since 2009 , when there was only one. These IT professionals are doing contract programming (within and outside of Cuba) and development services.

As one of the least connected countries in the world, Cuba has experienced sluggish growth in adopting and implementing Internet technology until recent years. Although its sad state of the Internet is a product of the island country's history, its emphasis on education, IT-related education in particular, has made its citizens highly capable of learning and catching up with latest advancements in Internet technologies. 


\section{Theoretical background: The theory of capital}

According to Bourdieu [2], both material and symbolic resources are essential to the competition. There are four basic forms of capital: symbolic, cultural, social, and economic [1]. Symbolic capital refers to accumulated honor and prestige, such as earning receiving awards. Cultural capital refers to the forms of knowledge embodied in culture, individual competencies, and institutional credentials, such as earning a college degree. Social capital refers to the social networks that one employs to improve social standing. According to Putnam [23], there are two types of social capital: bridging social capital and bonding social capital. The bridging social capital refers to loose connections between individuals who may provide useful information or new perspective to one another, while bonding social capital is found between individuals with emotionally close relationships such as family and close friends. Economic capital refers to monetary resources, such as property, stocks, and money. This capital is particularly germane to our study context of Cuban Internet, as news reports have indicated lack of financial resources one major barrier to Cuban's Internet access [24, 27]. In addition to the four forms of capital, Bourdieu [3] also recognized the need for technical capital to capture the specific skills required for interacting and engaging with modern computing equipment.

The different forms of capital can be converted under certain circumstances [1]. For example, one can convert economic capital (e.g., tuition payments) into cultural capital (e.g., a bachelor's degree). While conversion between the forms of capital can occur, the forms of capital are not reducible to each other. For instance, possession of cultural capital does not necessarily imply possession of economic capital: earning a college degree does not necessarily mean the degree holder can land in a high-paying job.

Using Bourdieu's framework, Joshi and colleagues [12] study the successful black men in the IT profession and inductively uncover that Black men succeed in IT careers by accumulating five forms of capital-cultural, social, symbolic, technical, and economic - that influence their decision making in pursuing IT careers. Similar to Joshi et al. [12], in this study, we focus on those Cuban citizens who had success with Intranet and Internet access, seeking to understand the forms of capital that enabled them to use Intranet/Internet while majority of the citizens in this country did not.

\section{Research method}

We conducted a qualitative, exploratory study to understand the forms of capitals that contributed to individual Internet access and use in Cuba. Consistent with the interpretive approaches to IS research outlined by Orlikowski and Barouli [14], our research intends to investigate how human actors made sense of technology use and practices in a developing country, rather than to hypothesize or test cause-and-effect relationships. In this regard, we followed the wellaccepted qualitative research methods articulated by Miles and Huberman [13] in the study.

\subsection{Data collection}

We designed and administered a national survey on cubava.cu, one of the most popular digital platforms in Cuba. Cubava.cu is a blog hosting service, which provides easy access to Cubans to access via the Intranet or Internet, and allows them to read and manage blogs with relative simplicity. "Reflejos" is the name of their blogging platform -- like Blogger.com or Wordpress.com. Cubans can create blogs there. We posted the survey on our Cuban co-author's blogging site and collected survey responses during the onemonth period of December 1 to December 31, 2016.

Our survey included both structured and unstructured questions on individual Internet access and related experiences. Rather than directly asking what barriers Cubans encountered during their Internet access and use, we asked them to share their experience in general. In this regard, we followed Friedman [7] by employing the indirect approach to engage informants' reasoning about the topic under investigation. The survey also included questions about their Internet tenure (how long they had been using the Internet), Internet use (frequency of connection and duration of each connection), and their demographics (e.g., gender; age; geographic location/province).

The survey was well received by the respondents and those with blogging sites even offered to spread out the word and promote the survey on their blogging pages. The following comment was typical:

"Very good your intention! I already have the link published in my blog xxxx.cubava.cu I have filled the whole survey, to see what results brings us this." [Dec. 5, 2016; User M]

\subsection{Sample characteristics}

Our data sample includes 82 users who responded to the key demographics questions and Intranet/Internet use questions in December 2016. The 
young users (21-30 years) accounted for more than half $(53.7 \%)$ of the respondents, followed by middle-aged users (31-40 years) at $25.6 \%$. Almost a half of the respondents $(46.3 \%)$ had Intranet and/or Internet access during the last three years; only a small portion of the respondents (13.4\%) had Intranet/Internet access for more than 10 years. Overall, about $91.4 \%$ of the respondents had Intranet experience, suggesting that their network access was often provided at workplace. The distribution of Intranet/Internet access by use experience and age groups is summarized in Table 1.

\begin{tabular}{|c|c|c|c|c|c|}
\hline \multicolumn{6}{|c|}{ By Years of Use Experience } \\
\hline & $\begin{array}{l}1-3 \\
\text { Years }\end{array}$ & $\begin{array}{l}3-5 \\
\text { Years }\end{array}$ & $\begin{array}{l}\text { 5-10 } \\
\text { Years }\end{array}$ & $\begin{array}{l}10+ \\
\text { Years }\end{array}$ & $\begin{array}{l}\text { Grand } \\
\text { Total }\end{array}$ \\
\hline Internet & $6.1 \%$ & $1.2 \%$ & $1.2 \%$ & $0.0 \%$ & $8.5 \%$ \\
\hline Intranet & $25.6 \%$ & $3.7 \%$ & $11.0 \%$ & $4.9 \%$ & $45.1 \%$ \\
\hline Both & $14.6 \%$ & $7.3 \%$ & $15.9 \%$ & $8.5 \%$ & $46.3 \%$ \\
\hline Total & $46.3 \%$ & $12.2 \%$ & $28.0 \%$ & $13.4 \%$ & $100.0 \%$ \\
\hline \multicolumn{6}{|c|}{ By Age Group } \\
\hline & $\begin{array}{l}14-20 \\
\text { Years }\end{array}$ & $\begin{array}{l}21-30 \\
\text { Years }\end{array}$ & $\begin{array}{l}31-40 \\
\text { Years }\end{array}$ & $\begin{array}{l}41-50 \\
\text { Years }\end{array}$ & $\begin{array}{l}51-60 \\
\text { Years }\end{array}$ \\
\hline Internet & $0.0 \%$ & $3.7 \%$ & $2.4 \%$ & $1.2 \%$ & $1.2 \%$ \\
\hline Intranet & $1.2 \%$ & $22.0 \%$ & $15.9 \%$ & $1.2 \%$ & $4.9 \%$ \\
\hline Both & $2.4 \%$ & $28.0 \%$ & $7.3 \%$ & $6.1 \%$ & $2.4 \%$ \\
\hline Total & $3.7 \%$ & $53.7 \%$ & $25.6 \%$ & $8.5 \%$ & $8.5 \%$ \\
\hline
\end{tabular}

Table 2 summarizes the distribution of Intranet/Internet use by access medium and access location.

\begin{tabular}{|c|c|c|c|c|}
\hline \multicolumn{5}{|c|}{ By Access Medium } \\
\hline & $\begin{array}{l}\text { Desktop } \\
\text { PC }\end{array}$ & Notebook & $\begin{array}{l}\text { Mobile } \\
\text { Phone }\end{array}$ & Total \\
\hline Internet & $4.9 \%$ & $1.2 \%$ & $2.4 \%$ & $8.5 \%$ \\
\hline Intranet & $45.1 \%$ & $0.0 \%$ & $0.0 \%$ & $45.1 \%$ \\
\hline Both & $37.8 \%$ & $3.7 \%$ & $4.9 \%$ & $46.3 \%$ \\
\hline Total & $87.8 \%$ & $4.9 \%$ & $7.3 \%$ & $100.0 \%$ \\
\hline \multicolumn{5}{|c|}{ By Access Location } \\
\hline & Home & Work & $\begin{array}{l}\text { Center \& } \\
\text { University }\end{array}$ & $\begin{array}{l}\text { WiFi \& } \\
\text { ETECSA } \\
\text { NAUTA }\end{array}$ \\
\hline Internet & $1.2 \%$ & $2.4 \%$ & $0.0 \%$ & $4.9 \%$ \\
\hline Intranet & $3.7 \%$ & $40.2 \%$ & $1.2 \%$ & $0.0 \%$ \\
\hline Both & $8.5 \%$ & $29.3 \%$ & $3.7 \%$ & $4.9 \%$ \\
\hline Total & $13.4 \%$ & $72.0 \%$ & $4.9 \%$ & $9.8 \%$ \\
\hline
\end{tabular}

As shown in Table 2, the dominant medium for Intranet/Internet access is desktop PC, as reported by $87.8 \%$ of the users in the sample. Only $12.2 \%$ of the respondents used notebook or mobile phone to access
Internet and Intranet. In addition, workplace remains the popular location for their Intranet/Internet, as reported by $72 \%$ of the respondents. Only $9.8 \%$ of the respondents reported accessing to Internet via $\mathrm{WiFi}$ and ETECSA Nauta. When they refer to Nauta, they mean the "navigation rooms" referred to above. These are facilities with a few online PCs.

The Intranet/Internet use (in terms of frequency) seemed to distribute across multiple categories, ranging from several times a day to once a month, as shown in Table 3. Of the 82 respondents, $34 \%$ accessed the network almost daily, followed by $24 \%$ with several times a day and $24 \%$ with several times a week. Among all those with daily access, $60 \%$ of them are Intranet users only, suggesting the access from workplace. For the small number of Internet users (8.5\% of the total), half of them reported accessing Internet a couple of times a month; only about $10 \%$ of them reported daily Internet access.

Table 3. Cuban Intranet/Internet use by frequency $(n=82)$

\begin{tabular}{|l|l|l|l|l|l|l|l|}
\hline & $(1)$ & $(2)$ & $(3)$ & $(4)$ & $(5)$ & $(6)$ & Total \\
\hline Internet & $0 \%$ & $1 \%$ & $2 \%$ & $1 \%$ & $4 \%$ & $0 \%$ & $8.5 \%$ \\
\hline Intranet & $13 \%$ & $21 \%$ & $10 \%$ & $0 \%$ & $1 \%$ & $0 \%$ & $45.1 \%$ \\
\hline Both & $11 \%$ & $12 \%$ & $12 \%$ & $5 \%$ & $5 \%$ & $1 \%$ & $46.3 \%$ \\
\hline Total & $24 \%$ & $34 \%$ & $24 \%$ & $6 \%$ & $10 \%$ & $1 \%$ & $100 \%$ \\
\hline
\end{tabular}

Note: frequency categories - (1) several times a day; (2)

almost every day; (3) several times a week; (4) once a week; (5) a couple of times a month; (6) once a month.

The duration time per Intranet/Internet access ranged from 15 minutes to 8 hours plus. For those with Intranet access, they most likely gained the access from workplace. The distribution of their reported time per connection is: $4-8$ hours $(21 \%), 2-4$ hours $(18 \%), 1-2$ hours $(16 \%)$, 30-60 minutes (12\%), less than 15 minutes (11\%), 15-30 minutes (9\%), and $8+$ hours $(6 \%)$. However, for those with public Internet access only, they reported duration time between 30 minutes and 2 hours per access. The distribution of duration time is summarized in Table 4.

Table 4. Cuban Intranet/Internet use by duration time ( $n=82)$

\begin{tabular}{|l|l|l|l|l|l|l|l|}
\hline & $(1)$ & $(2)$ & $(3)$ & $(4)$ & $(5)$ & $(6)$ & $(7)$ \\
\hline Internet & $0 \%$ & $0 \%$ & $4 \%$ & $4 \%$ & $0 \%$ & $0 \%$ & $1 \%$ \\
\hline Intranet & $5 \%$ & $4 \%$ & $6 \%$ & $10 \%$ & $9 \%$ & $12 \%$ & $0 \%$ \\
\hline Both & $6 \%$ & $5 \%$ & $6 \%$ & $6 \%$ & $9 \%$ & $9 \%$ & $6 \%$ \\
\hline Total & $11 \%$ & $9 \%$ & $16 \%$ & $20 \%$ & $18 \%$ & $21 \%$ & $7 \%$ \\
\hline
\end{tabular}

Note: duration categories-(1) less than 15 minutes; (2) 1530 minutes; (3) 30-60 minutes; (4) 1-2 hours; (5) 2-4 hours; (6) 4-8 hours; (7) $8+$ hours.

Males were dominant Intranet/Internet users in Cuba. In our data sample, males account for $87.8 \%$ (70 
users) and females $12.2 \%$ (12 users). All the 12 female users obtained access to Intranet/Internet from work, while male users reported access from other locations in addition to workplace. The majority (90\%) of the female users were between 21 and 40 years old.

For the collection of qualitative data, we asked our survey respondents open-ended questions on their experience with Intranet and Internet connection. We analyzed the written narratives from the respondents by following the well-accepted qualitative research methods outlined by Miles and Huberman [13]. For example, we started with open coding and codes suggested by Bourdieu's framework of capital [1], including the five types of capital. Then we revised codes (such as coding the improvisation behaviors) as we refined and clarified our theoretical interpretation.

\section{Findings}

Our analysis shows the two major barriers arising in Cuban's Internet user. Moreover, it reveals the four key capitals - economic, cultural, technical, and social - that the Cubans in our study possessed in their successful access to Intranet/Internet technology.

\subsection{Access barriers}

When responding to questions about their Internet/Intranet experience, our informants overwhelmingly talked about the speed and cost of the Internet connection. One user provided a detailed account of the two major barriers to network access:

"It is incredibly absurd but it is what we have. What are we going to do! In addition to this absurdity, we also have against us the connectivity they give us because it is limited and very minimum because we only have 1 mega of Wi-Fi. Which means that if you only pay for one hour for the high cost of it, you can hardly do anything, because it is extremely slow." [Dec. 2, 2016 by User L]

Another respondent shared this frustration of slow network connectivity and high cost, as shown below:

"[The Internet access] is still very expensive and for the average worker who lives on his salary. It is a bit difficult to be paying 50 pesos to have only one hour of connection that goes as water because of the slowness of it." [Dec. 1, 2016; User R]

There has been anecdotal evidence about the slow connection speed and high cost of Internet access in Cuba $[6,8]$. The narratives of our survey respondents provided nuances to enhance our understanding about those barriers.

\subsection{Forms of capital and Internet use}

Economic Capital: When responding to questions about their Internet/Intranet experience, our informants overwhelmingly talked about the expensive cost and slow connection. To the respondents, they were able to afford the money (e.g., 50 pesos) to pay for one hour of Internet access, indicating their possession of economic capital. Without sufficient economic capital, Cuban citizen could not afford to access the global Internet. The barriers to Internet use are evidenced in the following remarks:

"The internet via wifi is very bad and expensive." [Dec. 3, 2016; User Q.]

"I access about 3 times a week approximately 1 to 2 hours each time. It is also known by all, that the payment rates are excessively high because they are equivalent to a very high percentage of the basic salary of our country and only to sail for 1 hour." [Dec. 2, 2016; User L]

Cultural Capital: It refers to the forms of knowledge embodied in culture, individual competencies, and institutional credentials, such as earning a college degree. In Cuba, being a technician is associated with rich cultural capital because individuals with this title often had the advantage to access to internal Cuban Intranet and global Internet at work. As shown in the following, a respondent commented on those working professionals who spent almost 8 hours a day on Intranet and suggested their desirable occupations in the first remark. Another respondent suggested providing national Intranet would increase the cultural capital of the country.

"If you are working as you have time to review the intranet for almost 8 hours, what is your position or membership in your work center that allows you to review the Intranet. I think these are necessary questions because of this $88 \%$ of men on the web, I think $50 \%$ are laboratory technicians." [Dec. 2, 2016; User N]

"As long as I can connect, I think that the national intranet should be given free of charge and thus promote services for the technological development of the country." [Dec. 6, 2016; User R]

Technical capital: Technical skills are important for the Internet uses. In the meanwhile, accessing and navigating on the Intranet/Internet provided the users, technicians and software programmers with 
opportunities to search and acquire new knowledge. Internet and intranet users are developing skills, as exemplified in the following comments:

"I really use the intranet more than the internet but it is a tool for me of work that helps me increase and exceed my knowledge." [Dec. 5, 2016; User C]

"Internet give the programmers a place to put their jobs or to be provided with ADSL to create their own servers to generate content in the network that is very scarce." [Dec. 6, 2016; User R]

"I access systematically to the Internet, since I dedicate myself to the development of software, and really there it appears all the necessary documentation. In addition, I have a site in Cuba, xxxxxxx.cuba.cu, which I try to update systematically." [Dec. 1, 2016; User R1]

Social Capital: Having friends and family members online was the pre-condition for Cubans to communicate and strengthen their close ties. In this case, the possession of social capital contributed to Cuban's Intranet/Internet use. Meanwhile, having the access would allow Cubans to build new relationships via the online channel. This two roles of social capital are revealed in the two remarks below:

"They use it to communicate with family and friends, to investigate topics that interest them, leisure, music, shows, etc ... in general, it is being given a good use by users but, it is a pity that the service continues to be so expensive and so bad at the same time." [Dec. 12, 2016; User D.]

"What is needed is to expand the Internet in Cuba so that we can communicate better with other people inside and outside the country." [Dec. 13, 2016; User L]

\subsection{User adaptation}

In a country where the purchasing power of the locals is a $\$ 25$ per person per month, with \$25 equivalent to 687 pesos in 2015 [24], it would cause a financial burden to many Cubans if they have to spend 50 pesos -out of their 687 monthly salary-on one hour of network access. Under this circumstance, some users adapted their network access and usage behavior, such as accessing to Intranet (available at some workplaces) more frequently than to the global Internet. In other words, for those who have both Internet and Intranet accounts, their access frequency differed by the two types of network. In general, their Internet access was less frequently than Intranet access, as shown in the following remarks:
"If it is internet, I access almost once a month from the Nauta Wi-Fi or sometimes I go to the club 1, where there is a Nauta room. If it is intranet, I access a few times a week." [Dec. 1, 2016; User T]

"It would be interesting to know by what means people access the internet, what I say, I have a Facebook page, but I do not access it by own account, I do it through my sister at work or my husband's. I do not actually have access by other means." [Dec. 13, 2016; User N]

As reflected above, Cubans adapted to the high cost of Internet connection by regulating their frequency of network use or by choosing the location of access (e.g., Nauta WiFi spot or the Club). In some other cases, adaptation was made to work around the fluctuating or even abnormal connection speed by trying to connect from various locations. This is elaborated below:

"I am a regular user of the internet to update my blog, and I also communicate with family and friends. I have tried to connect in thousands of different places, at the most I achieve a normal connection when the number of people does not exceed 40 users but when this happens many times, the network is too slow." [Dec. 12, 2016; User D]

When resources are insufficient, users have to rely on workarounds to complete the tasks. This behavior can be explained by improvisation theory. Improvisation is defined as a set of unplanned actions in coping with technology, which lead to unplanned changes in the process of adoption or adaptation of new technologies [4].

\section{Discussion}

The objective of the study was to understand how Cubans are getting online and to uncover the forms of capital that contributed to Intranet/Internet use in Cuba. Our data analysis suggested that economic capital and cultural capital was the dominant factor contributing to Intranet/Internet Access, whereas social capital and technical capitals turned out to be the consequences of Intranet/Internet use.

The Internet access barrier caused by the lack of economic capital is similar to the findings in digital divide in the early development of Internet in U.S. Prior research has referred to digital divide as "the gap separating those individuals who have access to new forms of information technology from those who do not" [p. 499] and suggested that lack of possession of a computer and a network connection is considered the critical factor contributing to digital divide [9]. Second, 
one's social economics status (SES) -- including income, education, age, and race - were found to cause the access barriers. For example, income and education are two of the SES that positively correlated with levels of access to and familiarity with computers and the Internet in the U.S. more than fifteen years ago, according to National Telecommunications and Information Administration's reports [10].

Our data analysis did not reveal technical capital as a major contributing factor, although prior studies suggest that individual ability to take advantage of Internet access relies on the levels of information technology literacy among them. On the one hand, this surprising result might be partially explained by Cuban education and its emphasis of technical training. On the other hand, this may be due to the due to the factor that participants of the study have already possessed some good technical skills in Internet/Intranet.

Moreover, our analysis of the respondents' narratives reflects Cuban's value of Internet access for communication and knowledge acquisition. The Cubans in our survey frequently mentioned use of Internet for communication as the global telecommunication network allowed them to connect with their families and friends living in different places and countries, which is personally meaning to them. This finding is consistent with those reported by Aida Zekić [27] who interviewed 50 Cuban Internet users at nine WiFi hotspots in Havana during September and October 2016, and found that more than $90 \%$ of the 50 informants use the Internet for communication, such as making long-distance calls and using social media.

In addition to appreciating the network-enabled communication capability, our informants also expressed their appreciation of Internet access as a useful knowledge source. For example, some respondents elaborated on how they have improved their knowledge and gained competency in their field (such as software development) from accessing to the resources and documents online. Under these circumstances, Internet access has become personally meaningful to the Cuban citizens and enabled them to become more competent, thus generating a sense of empowerment. These cognitions of meaning and of competence reflect the two dimensions of empowerment discussed by Thomas and Velthouse [26]: the cognition of meaning reflects the personal meaningfulness of a job activity, and the cognition of competence reflects one's confidence about his/her skills and capabilities to do the work.

Due to the different capabilities of Internet and Intranet, it would be important to differentiate users' experience with the two types of network access. However, in our data set of 82 users, $46 \%$ of them reported having both Internet and Intranet access, $45 \%$ of them only had Intranet access, and 9\% of them had Internet only. The qualitative data from their narratives on their Internet/Intranet experience would not allow us to differentiate their Internet experience from Intranet experience. Since we collected some quantitative data on the three types of Internet use behaviors (years of experience, frequency of connection, and duration of a connection), we performed a Chi-Square Test to analyze the associations between type of user (Internet vs. Intranet) and three measures of Internet use behaviors. The chisquare analysis shows that Internet users are less likely to have access frequency of several times a day (Chisquare=2.131) compared to Intranet users. Internet users are more likely to have access frequency of couple of times a month (Chi-square=2.61), compared to Intranet users. In addition, Internet users are more likely to use mobile phone (Chi-square=5.853) and notebook (Chi-square=2.926) for access medium, compared to others. However, given the nature of the data sample, we are unable to make further statistical inference based on this data analysis.

\section{Contribution, limitation and future research}

In this paper, we reported the patterns of use of the Internet and Intranet by Cubans and explored the various forms of capital that affected their access and use. It enhanced our understanding of prominent forms of capital that contributed to the Internet/Intranet access Cuba. Currently academic studies of Cuba Internet remain limited: most articles and reports are based on anecdotal evidences. Focusing on individual viewpoints and analyzing their narratives, our study contributed to the studies of Internet in developing countries and made a first step in examining Cuban citizens' adoption and use of computer network technology from individual perspective.

Meanwhile, we would like to acknowledge the limitations of the study. First, given the difficulties of collecting large-scale survey data in Cuba, we collected data from online polls posted on a blogging site by our co-author located in Havana, Cuba. As a computer in the network might be shared by multiple users, a potential bias exists in this sampling approach. Initial findings form this exploratory study should be applied to other groups of users with caution. However, we tried to mitigate this bias by emphasizing unique responses among the visitors to the blogging site and by using IP host to identify unique responses. Second, our findings might be limited by the profiles of the respondents in our data sample, as they represented the minority of Cubans who have access to 
Internet/Intranet. However, we believe it was the best approach for us to elicit responses from those who have Internet/Intranet accounts, as our objective was to understand user perceptions associated with Internet use. Finally, as explained in the Discussion section above, we were not able to collect detailed data to separate an individual's experience of global Internet use from that of Intranet use.

There are three promising avenues for future research on Cuba Internet. First, our data analysis has shown that individual access and use patterns differed by the access locations (e.g., work, center/university or public WiFi hotspot). Moreover, their access frequency and duration differed by the type of users (Internet vs. Intranet) as reflected in Table 3 and elaborated above. A future study based on a large-scale survey data would generate interesting insights into the access and use of the two types of networks.

Second, the respondents to our survey suggested that the economic capital (e.g., financial resources) and social capital (e.g., higher education degree and working for a state software company) enabled them to get online. Yet, we did not have data about the sources of funds for using Internet; neither did we know if they work in the burgeoning IT profession in Cuba. According to a new report published on Havana Times, $62 \%$ of Cuban public Internet users receive mobile recharges from their relatives and friends abroad [25]. Thus, further study on the sources of economic and cultural capital for Cuban Internet use would generate promising insights.

Third, our data analysis has suggested improvisation behaviors by Cubans in their Intranet/Internet use. Improvisation theory is applicable in the organizational or team setting. According to Ciborra [4], improvisation occurs when existing and formal plans do not apply to novel situations at the appropriate time, and where key components, such as existing and explicit knowledge, access to resources and the ability to deploy them, and environmental surprises, exist. One promising direction for future studies on Cuba Internet use is to apply the improvisation theory into exploring technology use and adaptation in the Intranet/Internet-enabled work environment.

\section{Concluding remarks}

The International Telecommunication Union (ITU) publishes an annual report on "Trends in Telecommunication Reform" and in the 2015 edition, they defined four generations of telecommunication regulation, including: G1 for regulated public monopolies, G2 for basic reform of partial liberalization and privatization across the layers, G3 for enabling investment, innovation and access, and G4 based on integrated regulation. Cuba was not included in the analysis shown here because of insufficient data, but, if they had been, they would have clearly been a first-generation nation [18].

Moreover, the aforementioned $3 \mathrm{G}$ mobile trial illustrates Cuba's need to leapfrog technology. The ITU estimates there will be approximately 6.1 billion smartphones in the world by 2020 when we expect to see the first deployments of $5 \mathrm{G}$ mobile networks, which promise faster data transmission rates, increased coverage, and more [10]. Ironically, Cuba began a highly limited $3 \mathrm{G}$ trial less than a month after the ITU agreed on $5 \mathrm{G}$ performance requirements. Although the $3 \mathrm{G}$ coverage has slightly increased since then, Cuba should leapfrog landline and mobile technology, which will require leapfrogging infrastructure, ownership and regulation policy [18].

New information technologies have empowering impacts on a society. At the national level, Zheng [28] examined the role of new information technologies, especially the Internet, in facilitating political liberalization and making government more open, transparent, and accountable in China. In July 2017, Cuba Minister of Communications, Maimir Mesa Ramos spoke to the Cuban Parliament on the current state of the Internet and reviewed some recent achievements, including the assembling of tablets and laptops running the Cuban operating system, Nova, and the doubling of international bandwidth in 2016 from 4 $\mathrm{Gb} / \mathrm{s}$ to $8 \mathrm{~Gb} / \mathrm{s}$ [22]. Despite the achievements in Cuban Internet, concern about affordability of Internet access and migration of computer scientists to the nonstate sector are rising [22]. Given the high technical education and skills of Cuban citizens and their value in the Internet-enabled communication and knowledge acquisition, it remains an open, interesting question when Cuba government will provide all its citizens with open access to the global Internet so that Cubans can fully embrace the latest Internet technologies in the digital world.

\section{Acknowledgements}

We appreciated the support to the research project from Dean Joseph Wen at the College of Business Administration and Public Policy, California State University, Dominguez Hills (CSUDH). We thank the mini-track chairs and the two anonymous reviewers for their constructive comments.

\section{References}

[1] Bourdieu, P. (1986). 'The Forms of Capital', In J. Richardson (Ed.) Handbook of Theory and Research for the 
Sociology of Education, New York: Greenwood, pp. 241258.

[2] Bourdieu, P. (2011). "The forms of capital," Cultural theory: An anthology, pp. 81-93.

[3] Bourdieu, P. (2002). The Social Structure of the Economy, NY: Polity.

[4] Ciborra, C. U., Jr. (1996). The platform organization: Recombining strategies, structures, and surprises. Organization Science, 7(2), pp. 103-118.

[5] Ciborra, C. U., Jr. (1999). "Notes on improvisation and time in organizations," Accounting, Management and Information Technologies, 9(2), pp. 77-94.

[6] "Cuba announces broadband home internet project," $B B C$ News Report, February 1, 2016. URL: http://www.bbc.com/news/world-latin-america-35463423

[7] Friedman, B. (ed.). (1997). Human Values and the Design of Computer Technology, Cambridge and New York: Cambridge University Press.

[8] Griffith, E. (2016). "What it's like trying to get online in Cuba," Fortune News, April 22, 2016. URL: http://fortune.com/2016/04/22/cuba-internet-fail/

[9] Gunkel, D. J. (2003). "Second thoughts: Toward a critique of the digital divide," New Media \& Society, 5(4), pp. 499-522.

[10] International Telecommunications Union (ITU), 2015, "World Telecommunication/ICT Indicators database 2015 (19th Edition/December 2015)", ITU, Switzerland, 2015.

[11] International Telecommunications Union (ITU), 2016, "Measuring the Information Society Report", ITU, Geneva, Switzerland, 2016.

[12] Joshi, K. D., Kvasny, L., Unnikrishnan, P., \& Trauth, E. (2016, January). "How Do Black Men Succeed in IT Careers? The Effects of Capital". In Proceedings of the 49th Hawaii International Conference on Systems Science IEEE. pp. 4729-4738.

[13] Miles, M. B., and Huberman, A. M. (1994). Qualitative data analysis: An expanded sourcebook. Sage Publications, Incorporated.

[14] Orlikowski, W. \& Baroudi, J. (1991). Studying Information Technology in Organizations: Research Approaches and Assumptions. Information Systems Research, 2, pp. 1-28.

[15] Press, L. (2011). The state of the Internet in Cuba. Working paper (January 2011). URL: http://som.csudh.edu/fac/lpress/cuba/chapters/lpdraft2.docx
[16] Press, L. (2011). "The past present and future of the Internet in Cuba," Proceedings of the Twenty-first Annual Meeting of the Association for the Study of the Cuban Economy, Miami, August 4-6, 2011, pp. 186-193.

[17] Press, L. (2016). "Google Global Cache coming to Cuba" blog article published on December 9, 2016. URL: http://laredcubana.blogspot.com/2016/12/google-globalcache-coming-to-cuba.html

[18] Press, L. (2016). "Cuban telecommunication regulation in context," June 30, 2016. URL: http://laredcubana.blogspot.com/2016/06/cubantelecommunication-regulation-in.html

[19] Press, L. (2017). "Mobile coverage in Cuba -- mixed 2G and 3G," June 23, 2017. URL: http://laredcubana.blogspot.com/2017/06/mobile-coveragein-cuba-mixed-2g-and-3g.html

[20] Press, L. (2017). "How many licensed, self-employed programmers are there in Cuba?" April 15, 2017. URL: http://laredcubana.blogspot.com/2017/04/how-manylicensed-self-employed.html

[21] Press, L. (2017). "Cuban ICT statistics report for 2016", August 2, $2017 . \quad$ URL: http://laredcubana.blogspot.com/2017/08/cuban-ict-statisticsreport-for-2016.html

[22] Press, L. (2017). "Internet status report from Cuba's Minister of Communication," August 4, 2017. URL: http://laredcubana.blogspot.com/2017/08/internet-statusreport-from-cubas.html

[23] Putnam, R. D. (2000). "Bowling alone: America's declining social capital," In Culture and Politics, Palgrave Macmillan US, pp. 223-234.

[24] Rapoza, K. (2016). "Guess How Much Cubans Earn Per Month," Forbes. Published April 26, 2016. URL: https://www.forbes.com/sites/kenrapoza/2016/04/26/guesshow-much-cubans-earn-per-month/\#31ee25d667a5

[25] Robinson, C. (2016). "How Cubans Use WiFi Hotspots (Infographic)”, Havana Times, June 7, 2016. Http://www.havanatimes.org

[26] Thomas, K. W., and Velthouse, B. A. (1990). "Cognitive elements of empowerment: An 'interpretive' model of intrinsic task motivation," Academy of Management Review, 15(4), pp. 666-681.

[27] Zekić, A. (2017). ""Internet in Public: an ethnographic account of the Internet in authoritarian Cuba." Master Thesis, the University of Uppsala, Sweden.

[28] Zheng, Y. (2007). Technological empowerment: The Internet, state, and society in China. Stanford University Press. 